\title{
Predictors of Clinical Anxiety Aggravation at the End of a Cardiac Rehabilitation Program
}

\author{
Mozhgan Saeidi ${ }^{1}$; Saeid $\operatorname{Komasi~}^{1, *}$; Behzad Heydarpour ${ }^{1}$; Hossein Karim ${ }^{2}$; Mehdi Nalini ${ }^{3}$; \\ Parvin Ezzati ${ }^{1}$ \\ ${ }_{1}^{1}$ Department of Clinical Psychology, Cardiac Rehabilitation Center, Imam Ali Hospital, Kermanshah University of Medical Sciences, Kermanshah, IR Iran \\ ${ }^{2}$ Department of Cardiovascular Surgery, Imam Ali Heart Hospital, Kermanshah University of Medical Sciences, Kermanshah, IR Iran \\ ${ }^{3}$ Heart Researches Center, Imam Ali Heart Hospital, Kermanshah University of Medical Sciences, Kermanshah, IR Iran \\ ${ }^{*}$ Corresponding author: Saeid Komasi, Department of Clinical Psychology, Cardiac Rehabilitation Center, Imam Ali Hospital, Kermanshah University of Medical Sciences, Kermanshah, \\ IR Iran., Tel.: +98-8338380698, Fax:+98-8338360043, E-mail: S_Komasi63@yahoo.com
}

Received: May 19, 2015; Revised: June 13, 2015; Accepted: June 29, 2015

Background: Anxiety is one of the most primary and common reactions to a cardiac event can lead to hypertension, tachycardia, and high cardiac output.

Objectives: To investigate the predictors of clinical anxiety aggravation at the end of a cardiac rehabilitation (CR) program.

Patients and Methods: This retrospective study used a database of a CR ward of a hospital in Iran. The demographic and clinical information of 574 patients participating in the CR program from April 2005 through April 2010 were analyzed. In order to determine the predictors of anxiety, binary logistic regression was performed.

Results: After adjustment for gender, age and education, the results showed that $16.7 \%$ of the patients completed their CR program with increased levels of clinical anxiety. The following study variables were independently predictive of increased anxiety at the end of the CR program: male gender $(\mathrm{OR}=2.04,95 \% \mathrm{CI}=1.11$ to $3.33, \mathrm{P}=0.048)$, no history of diabetes $(\mathrm{OR}=4.24,95 \% \mathrm{CI}=172$ to $10.44, \mathrm{P}=0.002)$, family history of cardiac disease ( $\mathrm{OR}=2.63,95 \% \mathrm{CI}=1.03$ to $6.74, \mathrm{P}=0.043)$, and not quitting smoking $(\mathrm{OR}=3.29,95 \% \mathrm{CI}=1.38$ to $7.85, \mathrm{P}=0.007)$. These variables could explain $9 \%-15 \%$ of the variance in the dependent variable.

Conclusions: It is possible to predict higher anxiety levels at the end of the CR program and implement preventive measures to control anxiety by considering certain demographic and clinical variables. Future studies should assess the predictive power of other variables.

Keywords: Anxiety; Cardiac Patients; Cardiac Rehabilitation; Demographic Factors; Clinical Factors

\section{Background}

Anxiety is one of the most primary and common reactions to a cardiac event (1) can lead to hypertension, tachycardia, and high cardiac output (2). Anxiety plays a crucial role in the development and stabilization of cardiac diseases (3), to the extent that $22 \%$ of patients with cardiac conditions have reported anxiety to be the main cause of their illness $(4,5)$. Consequently, participating in cardiac rehabilitation (CR) programs can decrease psychological complications in patients (6-8). CR is among the main interventions recommended after a cardiac event or heart surgery in order to minimize possible complications such as anxiety $(1,9,10)$. CR involves education on a healthy lifestyle to prevent chronic diseases or disabling conditions., and its aim is to restore patients to their highest possible physical, mental, social, and occupational capabilities (11). CR programs are conducted to improve patients' psychological and social state, to limit the physical and psychological effects of cardiovascular diseases, to minimize the risk of sudden death or repeated myocardial infarction, and to control symptoms arising from coronary artery disease (12). However, some patients may experience anxiety even at the end of CR programs. Anxiety is determined in cardiac patients by observing their inability to predict, control, or achieve the desired treatment results $(13,14)$. Anxiety is related to physical performance, ability, and quality of life in patients with chronic cardiac disease (15-17). High levels of anxiety increase the risk of heart attack by up to three times (2). It is therefore essential to determine the causes of increasing anxiety in cardiac patients at the end of the CR program in order to prevent possible negative consequences. Furthermore, at least two sessions of exercise per week are included in the structure of outpatient CR by hospitals, which lasts for 8 to 12 weeks. During this time, however, patients are expected to be compliant with the recommended regimen. For this reason, it is necessary to determine the factors that increase anxiety in patients.

Copyright (C) 2016, Rajaie Cardiovascular Medical and Research Center, Iran University of Medical Sciences. This is an open-access article distributed under the terms of the Creative Commons Attribution-NonCommercial 4.0 International License (http://creativecommons.org/licenses/by-nc/4.0/) which permits copy and redistribute the material just in noncommercial usages, provided the original work is properly cited. 


\section{Objectives}

The present study investigates the predictors of clinical anxiety aggravation at the end of a CR program.

\section{Patients and Methods}

\subsection{Study Design}

This was a retrospective study. Data were obtained from the CR center of Imam Ali Hospital in Kermanshah city, Iran. Imam Ali Hospital is a governmental cardiac specialized center in Western Iran that is generally visited by residents of this region. This database contained information about cardiac patients, especially those who had undergone coronary artery bypass graft surgery (CABG) or percutaneous coronary intervention (PCI) and those who had received a diagnosis of myocardial infarction (MI) or valvular heart disease (VHD), who had registered in the CR program after experiencing a cardiac event. The database contained patients' demographic and clinical data, including type of cardiac problem or the treatment method, comorbid conditions, and type of procedure performed. The registration forms were designed by cardiologists, health specialists, and experts under the supervision of Kermanshah university of medical sciences. The inspection unit of the university assesses the accuracy of the data twice a year. The present study examines which demographic and clinical variables can be used to identify patients who are likely to be unable to complete the CR program with decreased anxiety. This will improve overall performance of the CR ward. Before beginning the program, patients are assessed for psychological disorders like depression and anxiety with standard tools, such as the Beck Depression Inventory and the Beck Anxiety Inventory. In case the patient is illiterate, the tools are read out to him or her by the clinical psychologist based in the CR ward, who then records the patient's responses. Anxiety aggravation at the end of the CR program was treated as a binary variable in this study (yes/no), in order to determine its predictors. This study was approved by the ethics committee of the Kermanshah university of medical sciences, Iran.

\subsection{Study Population}

A total of 738 patients participated in the CR program over a period of five years, between April 2005 and 2010. Although all patients' data were entered into the analysis, some of the patients between 2005 and 2006 had missing information for some items. Hence, 164 patients were excluded. The final sample comprised 574 persons.

\subsection{Instruments}

The Beck anxiety inventory (BAI): This questionnaire was designed by Beck in 1988 and is comprised of 21 items, rated on a 3-point scale. The total score ranges from 0 to 63. Scores between 0 and 7 indicate no anxiety; scores from
8 to 15 , mild anxiety; scores from 16 to 25 , moderate anxiety; and scores from 26 to 63, severe anxiety. The internal consistency coefficient (Cronbach's alpha) of the inventory was 0.92. In an assessment of test-retest reliability with a one-week interval, the correlation coefficient was 0.75 and item internal consistency coefficients ranged from 0.30 to 0.76 . In the present study, five types of validity were assessed (content, concurrent, component, diagnostic, and operative). All assessments indicated that the tool is a highly appropriate measure of anxiety (18).

\subsection{Statistical Analysis}

The patients were categorized into two groups: patients who completed the CR program with increased anxiety and those who completed the program with decreased anxiety. The characteristics of the two groups were compared using a chi-squared test for categorical variables and a one-way analysis of variance (ANOVA) for continuous variables. Continuous variables were summarized as means and standard deviations and non-continuous variables were summarized as frequencies and percentages. Binary logistic regression was used to identify sociodemographic and clinical factors related to quitting the CR program. Gender, age, marital status, level of education, treatment procedures (CABG, PCI, MI, and VHD), cardiovascular risk factors (diabetes, cholesterol level, and BMI [body mass index]), family history, and history of smoking were all entered into the analysis. The significance threshold was set as 0.05, IBM SPSS Statistics 21 for Windows (IBM Inc., Armonk, NY) was used for the statistical analysis.

\section{Results}

Of the 574 patients (453 males and 121 females) who participated in the CR program and whose data were entered into the analysis, 96 (16.7\%) completed the program with increased anxiety and 478 (83.3\%) had decreased anxiety. Table 1 shows the sociodemographic and clinical characteristics of the subjects, also categorized by whether they completed the program with increased or decreased anxiety. At the baseline, men were more likely than women and employed individuals were more likely than housewives to complete the CR program with increased anxiety $(\mathrm{P}=0.001)$. Patients with no history of diabetes $(\mathrm{P}=0.005)$ were more likely than patients with such a history to complete the program with increased anxiety.

Table 2 shows the adjusted odds ratios, 95\% confidence intervals, and Pvalues for each covariate included in the binary logistic regression model. The statistical assumptions for binary logistic regression were met. The model was statistically significant overall $\left(\chi^{2}=53.864, \mathrm{P}<0.001\right)$. Of the 24 variables included as covariates in the regression, four had independent significant associations with increased anxiety. Indicators of effect size showed only low explanatory power with respect to increased anxiety (Cox and Snell $\mathrm{R}^{2}=$ 0.090, Nagelkerke $\mathrm{R}^{2}=0.151$ ). 
Saeidi M et al.

\begin{tabular}{|c|c|c|c|c|}
\hline Characteristic & $\begin{array}{c}\text { Total Sample, } \\
\mathrm{n}=\mathbf{5 7 4}\end{array}$ & $\begin{array}{l}\text { Decreased Anxiety, } \\
n=478(83.3 \%)\end{array}$ & $\begin{array}{l}\text { Increased Anxiety, } \\
\quad \mathbf{n}=96(16.7 \%)\end{array}$ & P Value $^{c}$ \\
\hline \multicolumn{5}{|l|}{ Demographic characteristics } \\
\hline Gender & & & & 0.001 \\
\hline Male & 78.9 & 76.4 & 91.7 & \\
\hline Female & 21.1 & 23.6 & 8.3 & \\
\hline Age, $y$ & $55.5 \pm 8.55$ & $55.7 \pm 8.55$ & $54.5 \pm 8.49$ & 0.21 \\
\hline Education degree & & & & 0.99 \\
\hline Illiterate & 32.5 & 32.4 & 32.3 & \\
\hline Less than diploma & 27.5 & 27.4 & 27.1 & \\
\hline Diploma & 22.6 & 22.8 & 21.9 & \\
\hline Academic & 17.4 & 17.4 & 18.7 & \\
\hline Marital status & & & & 0.13 \\
\hline Married & 96.3 & 95.8 & 98.9 & \\
\hline Single, Divorced, or Separated & 3.7 & 4.2 & 1.1 & \\
\hline Occupation & & & & 0.001 \\
\hline Seller & 30.3 & 28.7 & 38.5 & \\
\hline Clerk & 20.2 & 18.8 & 28.1 & \\
\hline Retired & 30.0 & 30.3 & 27.1 & \\
\hline Housewife & 19.5 & 22.2 & 6.3 & \\
\hline
\end{tabular}

\section{Clinical characteristics}

\begin{tabular}{|c|c|c|c|c|}
\hline Index procedure & & & & 0.47 \\
\hline CABG & 95.5 & 95.4 & 95.8 & \\
\hline VHD & 1.4 & 1.7 & 0.0 & \\
\hline PCI & 1.9 & 1.7 & 3.1 & \\
\hline MI & 1.2 & 1.2 & 1.1 & \\
\hline \multicolumn{5}{|l|}{ Cardiac risk factors } \\
\hline Diabetes & 35.4 & 37.9 & 22.9 & 0.005 \\
\hline Hypertension & 29.8 & 28.9 & 34.4 & 0.28 \\
\hline Hyperlipidemia & 53.5 & 53.3 & 54.2 & 0.88 \\
\hline Family history & 24.6 & 25.3 & 20.8 & 0.35 \\
\hline BMI, $\mathrm{kg} / \mathrm{m}^{2}$ & $26.40 \pm 3.40$ & $26.41 \pm 3.46$ & $26.37 \pm 3.14$ & 0.92 \\
\hline Number of risk factors & $2.4 \pm 1.3$ & $2.4 \pm 1.3$ & $2.3 \pm 1.3$ & 0.64 \\
\hline History of smoking & & & & 0.35 \\
\hline Never smoked & 67.8 & 67.2 & 70.8 & \\
\hline Ceased smoking & 25.9 & 27.0 & 20.8 & \\
\hline Active smoker & 6.3 & 5.8 & 8.3 & \\
\hline
\end{tabular}

a Qualitative values are presented as mean \pm SD, Quantitative values are preented as percentage.

b Abbreviations: BMI, body mass index; CABG, coronary artery bypass graft surgery; MI, myocardial infarction; $\mathrm{PCI}$, percutaneous coronary intervention; VHD, valvular heart disease.

${ }^{\mathrm{C}}$ A chi-square test was performed for nominal and categorical variables; an ANOVA was performed for continuous variables. 
Saeidi M et al.

\begin{tabular}{|c|c|c|c|}
\hline Characteristic & Increased Anxiety $^{a}$ & Adjusted Odds Ratio (CI95\%) & P Value \\
\hline \multicolumn{4}{|l|}{ Demographic characteristics b } \\
\hline \multicolumn{4}{|l|}{ Gender } \\
\hline Female & 6.6 & - & \\
\hline Male & 19.4 & $2.04(1.11-3.33)$ & 0.048 \\
\hline Age & - & $1.07(0.99-1.11)$ & 0.21 \\
\hline \multicolumn{4}{|l|}{ Education degree } \\
\hline Illiterate & 16.7 & - & \\
\hline Less than diploma & 16.6 & $0.66(0.12-3.64)$ & 0.64 \\
\hline Diploma & 16.2 & $0.89(0.07-10.77)$ & 0.93 \\
\hline Academic & 17.8 & $0.03(0.00-1.57)$ & 0.08 \\
\hline \multicolumn{4}{|l|}{ Marital status } \\
\hline Married & 17.2 & - & \\
\hline Single, Divorced, or Separated & 4.8 & $2.66(0.33-21.77)$ & 0.36 \\
\hline \multicolumn{4}{|l|}{ Occupation } \\
\hline Seller & 21.3 & - & \\
\hline Clerk & 22.4 & $0.88(0.43-1.82)$ & 0.74 \\
\hline Retired & 15.7 & $1.29(0.65-2.58)$ & 0.46 \\
\hline Housewife & 5.3 & $4.34(0.32-57.96)$ & 0.27 \\
\hline \multicolumn{4}{|l|}{ Clinical characteristics } \\
\hline \multicolumn{4}{|l|}{ Index procedure } \\
\hline CABG & 16.8 & - & \\
\hline VHD & 0.00 & $0.58(0.09-6.22)$ & 0.99 \\
\hline PCI & 27.3 & $0.51(0.11-2.30)$ & 0.38 \\
\hline MI & 14.3 & $1.93(0.20-18.31)$ & 0.57 \\
\hline \multicolumn{4}{|l|}{ Cardiac risk factors } \\
\hline Diabetes & 10.8 & $4.24(1.72-10.44)$ & 0.002 \\
\hline Hypertension & 19.3 & $1.09(0.45-2.62)$ & 0.85 \\
\hline Hyperlipidemia & 16.9 & $1.76(0.76-4.04)$ & 0.18 \\
\hline Family history & 14.2 & $2.63(1.03-6.74)$ & 0.043 \\
\hline $\mathrm{BMI}, \mathrm{kg} / \mathrm{m}^{2}$ & - & $1.03(0.92-1.15)$ & 0.61 \\
\hline Number of risk factors & - & $0.50(0.25-1.02)$ & 0.056 \\
\hline \multicolumn{4}{|l|}{ History of smoking } \\
\hline Never smoked & 17.5 & - & \\
\hline Ceased smoking & 13.4 & $3.29(1.38-7.85)$ & 0.007 \\
\hline Active smoker & 22.2 & $1.52(0.53-4.38)$ & 0.44 \\
\hline
\end{tabular}

\footnotetext{
a Abbreviations: BMI, body mass index; CABG, coronary artery bypass graft surgery; MI, myocardial infarction; PCI, percutaneous coronary intervention; VHD, valvular heart disease.

$\mathrm{b}$ The demographic and clinical characteristics listed in this table were all included as covariates in the binary logistic regression model. One odds ratio for each characteristic was statistically significant.
} 
After adjustment for gender, age, and education, the analysis showed that the following were more likely to complete the CR program with increased anxiety: male patients $(\mathrm{OR}=2.04,95 \% \mathrm{CI}=1.11$ to $3.33, \mathrm{P}=0.048)$, those who did not quit smoking $(\mathrm{OR}=3.29,95 \% \mathrm{CI}=1.38$ to 7.85 , $\mathrm{P}=0.007)$, and individuals with no history of diabetes ( $\mathrm{OR}=4.24,95 \% \mathrm{CI}=172$ to $10.44, \mathrm{P}=0.002)$ and a positive family history for cardiac disease $(\mathrm{OR}=2.63,95 \% \mathrm{CI}=1.03$ to $6.74, \mathrm{P}=0.043$ ).

\section{Discussion}

The present study investigated the predictors of clinical anxiety aggravation at the end of a CR program. The results indicated that being male, smoking, being nondiabetic, and having a positive family history for cardiac disease were related to aggravated anxiety at the end of the program. While participating in CR programs may minimize psychological symptoms such as anxiety and depression in cardiac patients in the short term, further research in this regard is needed (10). The present study showed that not only did many patients show no decrease in anxiety symptoms but also anxiety increased in several participants. Being male was a significant predictor of increased anxiety. Modica et al. (19) found that the different ways in which male and female cardiac patients frequencies and percentages their disease may be related to the outcomes of a CR program. They pointed out that men use denial mechanisms significantly more often than women do. In male patients, denial of the present situation is followed by treatment resistance, which can exacerbate anxiety in different ways. For instance, resistance manifests in indifferent participation in the psychology training sessions, passivity in acquiring ability to perform reaction capabilities, and refusal to do homework, all of which may exacerbate anxiety symptoms. Moreover, at the very early stages of the program, these patients might under-report their anxiety in the questionnaire. However, during the CR program, they lower their guard, and consequently, at the end of the program, their anxiety levels seem to have increased despite improvements in mood.

Other research found that patients without diabetes were more vulnerable to increases in anxiety at the end of the CR program. Saeidi et al. (4) showed that nearly $3 \%$ of CR patients believe that diabetes is the main cause of their illness. Twice as more women than men had this belief. Persons with diabetes may relate their cardiac condition to diabetes. Therefore, by controlling diabetes through medication, appropriate diet, and physical exercise during the CR program, these patients are no longer worried about this risk factor. While such patients believe that they have control over the main cause of their present cardiac condition, patients without diabetes may not be able to even find a reasonable cause for their cardiac condition. Saeidi et al. (5) found that more than $10 \%$ of cardiac patients are unable to relate their illness to a risk fac- tor. Thus, it seems that failure to relate the cardiac condition to a risk factor, such as diabetes, can increase anxiety because of the feeling of not having control over the illness. In line with this idea, Michie et al. (20) examined the feeling of control over health consequences and pointed out that an increase in this feeling decreases mental pressure and anxiety in cardiac patients. Therefore, when patients do not feel a sense of control over their conditions, their anxiety is bound to increase despite participation in $\mathrm{CR}$ programs.

This idea could be extended to patients without a positive family history, who were also found to have increased anxiety. As they probably cannot determine the cause of their illness, they too will lack a sense of control.

Moreover, we observed that patients who were still smokers experienced higher levels of anxiety than those who quit. Another study (21) noted a significant relationship between smoking and anxiety and found that anxiety and depression are the commonest comorbidities of smoking. The concept of cognitive inconsistency could explain this result: When an individual is confronted by two thoughts and recognizes that their simultaneous existence is impossible, he or she experiences tension and disorientation (22). Therefore, cardiac patients who still smoke actively despite the recommendations of the $C R$ team and their own knowledge of the increasing dangers and negative consequences of smoking, will suffer from cognitive inconsistency, which can ultimately lead to increased anxiety at the end of the CR program.

One of the limitations of the present study was missing data, which led the statistical software to exclude some patients from the analysis. This issue makes it difficult to generalize the present findings to other patients and CR centers. Another limitation was limited number of female participants. Therefore, future studies should include samples with a more balanced gender distribution. Yet another limitation was the retrospective nature of the data. Furthermore, we were not able to control for all possible confounding variables. Therefore, the impact of such confounders must be controlled for in the future studies. Finally, the small R-square values obtained from the regression analysis indicate that there are other potential predictors that have not been assessed. Future studies should attempt to identify these factors and determine their predictive power.

\section{Authors' Contributions}

1. Study concept and design: Saeid Komasi. 2. Acquisition of data: Mozhgan Saeidi. 3. Analysis and interpretation of data: Mozhgan Saeidi and Parvin Ezzati. 4. Drafting of the manuscript: Behzad Heydarpour. 5. Critical revision of the manuscript for important intellectual content: Hossein Karim. 6. Statistical analysis: Saeid Komasi. 7. Administrative, technical and material support: Mehdi Nalini. 8. Study supervision: Mozhgan Saeidi. 


\section{References}

1. Bath J, Bohin G, Jones C, Scarle E. Cardiac Rehabilitation: a workbook for use with group programmes. Chicester: Wiley-Blackwell; 2009.

2. Karami J, Komasi S, Maesoomi M, Saeidi M. Comparing the effects of two methods of relaxation and interpersonal cognitive problem solving (ICPS) on decreasing anxiety and depression in cardiac rehabilitation patients. Urmia Med J. 2014;25:298-308.

3. Saeidi M, Komasi S, Heydarpour B, Momeni K, Zakiei A. Those Who Perceive Their Disease as a Physiological or Psychological Risk Factor Experience More Anxiety at the Beginning of Cardiac Rehabilitation Program. Res Cardiovascular Med. 2015:e29291.

4. Saeidi M, Komasi S, Soroush A, Zakiei A, Shakeri J. Gender Differences in Patients' Beliefs About Biological, Environmental, Behavioral, and Psychological Risk Factors in a Cardiac Rehabilitation Program. JCar thorac Med. 2014;2(4):215-20.

5. Saeidi M, Soroush A, Komasi S, Heydarpour B, Momeni K. Attitudes Toward Cardiovascular Disease Risk Factors Among Patients Referred to a Cardiac Rehabilitation Center: Importance of Psychological Attitudes. . Shiraz E Med J . 2015;16(7):22281.

6. Lavie CJ, Milani RV, Lavie TJ. Impact of Cardiac Rehabilitation, Exercise Training, and Fitness on Psychological Distress. In: Sher L, editor. Psychological factors and cardiovascular disorders: The role of stress and psychological influences. New York: Nova Science Publishers; 2009. pp. 314-20.

7. Kim C, Kim DY, Moon CJ. Prognostic Influences of Cardiac Rehabilitation in Korean Acute Myocardial Infarction Patients. Ann Rehabil Med. 2011;35(3):375.

8. Soroush A, Heydarpour B, Saeidi M, Komasi S, Ezzati P, Rashidi AA. Cardiac Disease Risk Factors In Cardiac Rehabilitation Patients with and without Depression.; 1st international congress of cardiac rehabilitation.; Isfahan, Iran. 2014.

9. Libby P, Bonow RO, Mann D, Zipes DP. Braunwald's Heart Disease: A Textbook of Cardiovascular Medicine. 8 ed. Philadelphia: Elsevier Science; 2007.

10. Vaccarino V, Bremner JD. Psychiatric and Behavioral Aspects of Cardiovascular Disease. In: Bonow RO, Mann DL, Zipes DP, Libby P, Braunwald E, editors. Braunwald's Heart disease: A text book of cardiovascular medicine. 9 ed. Philadelphia: Saunders; 2012. p. 1908.
11. World Health Organization. Needs and action priorities in cardiac rehabilitation and secondary prevention in patients with coronary heart disease. Geneva: WHO Regional Office for Europe. 1993:6.

12. Williams MA, Ades P, Hamm LF, Keteyian SJ, LaFontaine TP, Roitman JL, et al. Clinical evidence for a health benefit from cardiac rehabilitation: An update. Am Heart J. 2006;152(5):835-41.

13. Compare A, Germani E, Proietti R, Janeway D. Clinical Psychology and Cardiovascular Disease: An Up-to-Date Clinical Practice Review for Assessment and Treatment of Anxiety and Depression. Clin Pract Epidemiol Ment Health. 2011;7:148-56.

14. Lau Walker M. Importance of illness beliefs and self-efficacy for patients with coronary heart disease. $J$ Adv Nursing. 2007;60(2):187-98.

15. Le Grande MR, Jackson AC, Murphy BM, Thomason N. Relationship between sleep disturbance, depression and anxiety in the 12 months following a cardiac event. Psychol Health Med. 2015:1-8.

16. Kinley DJ, Lowry H, Katz C, Jacobi F, Jassal DS, Sareen J. Depression and anxiety disorders and the link to physician diagnosed cardiac disease and metabolic risk factors. Gen Hosp Psychiatry. 2015;37(4):288-93.

17. Seo J, Lee Y, Kang S, Chun H, Pyun WB, Park SH, et al. Poor HealthRelated Quality of Life and Proactive Primary Control Strategy May Act as Risk Factors for Acute Coronary Syndrome. Korean Circ J. 2015;45(2):117.

18. Beck AT, Epstein N, Brown G, Steer RA. An inventory for measuring clinical anxiety: Psychometric properties. J Cons Clin Psychol. 1988;56(6):893-7.

19. Modica M, Ferratini M, Spezzaferri R, De Maria R, Previtali E, Castiglioni P. Gender Differences in Illness Behavior After Cardiac Surgery. J Cardiopulm Rehabil Prev. 2014;34(2):123-9.

20. Michie S, O'Connor D, Bath J, Giles M, Earll L. Cardiac rehabilitation: The psychological changes that predict health outcome and healthy behaviour. Psychol Health Med. 2005;10(1):88-95.

21. Mykletun A, Overland S, Aarø LE, Liabø HM, Stewart R. Smoking in relation to anxiety and depression: Evidence from a large population survey: The HUNT study. Euro Psychiatry. 2008;23(2):77-84.

22. Hasan U. Cognitive Dissonance and Its Impact On Consumer Buying Behaviour. IOSR J Bus Manage. 2012;1(4):7-12. 